\title{
Taqwīm Istima` Khilālu Fitratul Al-Wabā' Fī Ma`hād As-salam Tanjung Pura
}

\author{
Nuradela Afriza ${ }^{1}$ \\ ${ }^{1}$ Institut Agama Islam Negeri Langsa \\ ${ }^{1}$ Nuradela223@gmail.com
}

$\begin{array}{ccc}\text { First received: } & \text { Revised: } & \text { Final Accepted: } \\ \text { 11 October 2021 } & \text { 30 December 2021 } & \text { 31 December 2021 }\end{array}$

\begin{abstract}
Abstrak
Peneliti berusaha mengkaji tentang bagaimana evaluasi pembelajaran yang digunakan dalam proses pembelajaran berlangsung. Selama pandemi berlangsung peneliti melihat bahwa evaluasi di pondok pesantren tersebut berkurang atau masih tergolong rendah, hal ini dikarenakan tidak efektifnya waktu siswa dalam kegiatan belajar mengajar dan dikarenakan minimnya waktu guru tidak memberi evaluasi harian terhadap siswa, sehingga siswa tidak mengetahui sampai dimana pemahaman belajar yang diperoleh. Tujuan penelitian ini untuk mengetahui bagaimana standart evaluasi siswa selama pandemi, dan bagaimana guru memberi evaluasi istima' siswa selama pandemi. Metode yang dilakukan dalam penelitian ini adalah Kualitatif Deskriptif. Penelitian ini dilakukan di pondok pesantren al-ikhwan as-salam Tanjung Pura. Adapun instrumen penelitian yang digunakan adalah: observasi, wawancara dokumentasi, yang menjadi sumber data dalam penelitian ini adalah kepala sekolah, dan guru bahasa Arab istima'. Setelah diperoleh hasil penelitian ini, peneliti mendapatkan data bahwasannya evaluasi pembelajaran Istima' Selama Pandemi Di Pondok Pesantren Al-Ikhwan As-Salam Tanjung Pura adalah: perbedaan dalam standart evaluasi selama pandemi dan sebelum pandemi tidak ada hanya saja waktu dan jam pembelajaran yang dikurangkan. Adapun guru dalam memberi evaluasi dengan menggunakan video yang terbagi menjadi dua level: level A dan Level B, kemudian murid mendengarkan lafal yang benar sesuai pendengaran masing-masing, dan mengisi titik-titik.
\end{abstract}

Kata Kunci: Pembelajaran Istima', Pembelajaran masa Covid 19 
أ- أ- - مقدمة

التعليم هو عملية لتوفير بيئة بحيث يمكن للطلبة التعاقد مع البيئة لتطوير قدراتهم الحالية. هذه القدرة في شكل قدرات معرفية، وهي شحذ المعرفة، والمهارات العاطفية شحذ الحساسية العاطفية، والمهارات الحركية النفسية أي شيء المهارات. هذه القدرات الثلاث فقال Binyamin S.Bloom من المتوقع أن يتم إطلاق سراح الطلبة إلى فرد مستعد لدخول العالم خارج المدرسة. التعليم هو الشكل الأكثر فعالية لعملية تشكيل الشخصية، لأنه في التعليم سوف تعطى واحدة التوجيه والتوجياء للذهاب في اتجاه أفضل وهذا هو وفقا للمعايير. المدرسـة هي مؤسسة تعليمية رسمية توفر فرصا مختلفة للطلبة للقيام بأنشطة التعليم.

تقويم هو جزء مهم جدا من عملية تعليم اللغة العربية. التقويم هو القياس والنتائج. القياس ذات صلة بالحجم. التقويم هو عملية مستمرة، قبل وأثناء وبعد عملية تعليم اللغة العربية. عملية التقويم توجياه إلى هدف محدد، وهي الحصيول على إجابات حول كيفية تحسين التدريس. تققويم التعليم من خلال الاختبارات. الاختبار هو مقياس. التعليم معرفة بكلمة "التدريس" يأتي من الكلمة الأسـاسية "تعليم" وهو ما يعني

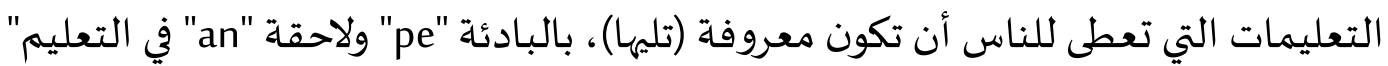
وهو ما يعني عملية التدريس أو التدريس بحيث يرغب الطلبة في التعليم. وبعبارة أخرى، فإن أنشطة التعليم هي أنشطة توجد فيها عملية تأديب وتوجيه وتدريب وأمثلة وتنظيم وتيسير الأمور للطلبة من أجل تحقيق الأهداف التعليمية. كما يعرف

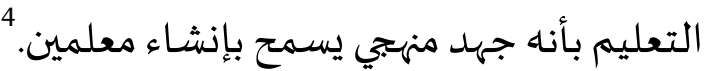
الاستماع هو عملية تلقي مجموعة من الميزات الصهوتية الواردة في المفردات، أو الجملة التي لها معنى يتعلق الكلمة السابقة، في موضهوع معين. كما يمكن تفسير الاستماع على أنه فهم لمختلف الفروق الدقيقة في معنى النصوص الشفوية المختلفة مع مجموعة

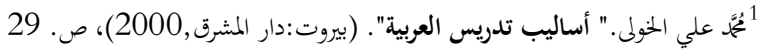

${ }^{2}$ Suyadi, "strategi pembelajaran pendidikan karakter",(Bandung : PT. RemajaRosdakarya , 2013), hal.4

${ }^{3}$ Suharsimi Arikunto, "Dasar-Dasar Evaluasi pendidikan", (Jakarta : Bumi Aksara, 2018), hal .45

${ }^{4}$ Nur Balqis, Meutia Rahmah, "Media Pembelajaran Bahasa Arab", (Langsa : Zawiyah Serambi Ilmu Pengetahuan 2015), hal. 1 
متنوعة من أغراض وسياقات الاتصال، ويعريف عبد المجيد سيد أحمد منصهور الاستماع: أي عملية الاستماع بجدية إلى رموز اللغة المنطوقة ثم تفسيرها.

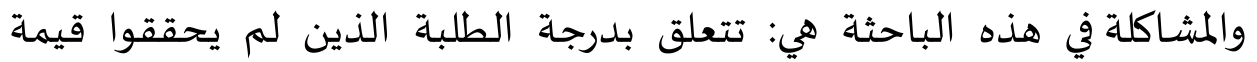

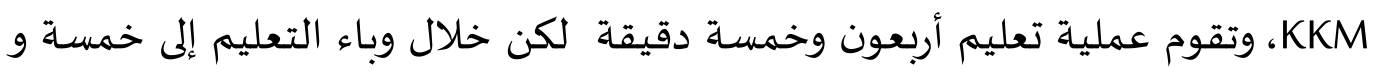

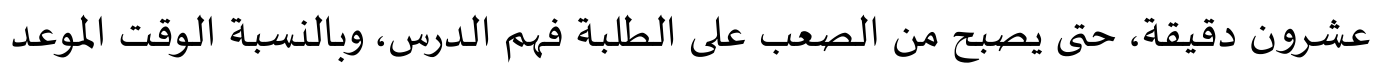

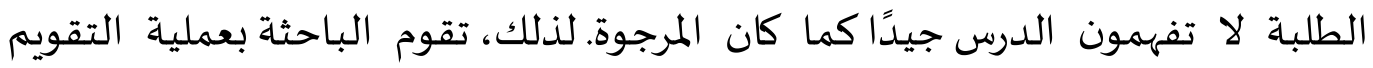

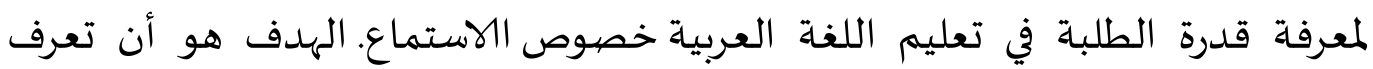

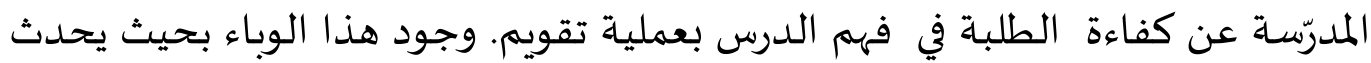

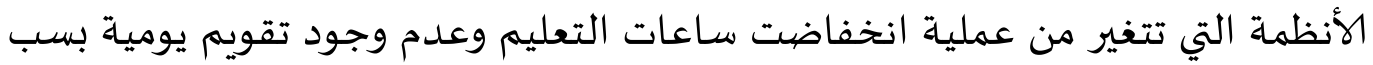
تطبق هذه المدرسة لوائح من الحكومة والوزارة حيث يمكن للطلبة تنفيذ التعليم كالمعتاد ولكن تجب على المدرّسة تقليل وقت التعليم.

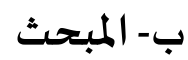

\section{أ- الاستماع ومباحثها 1}

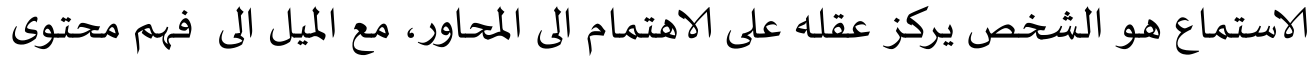

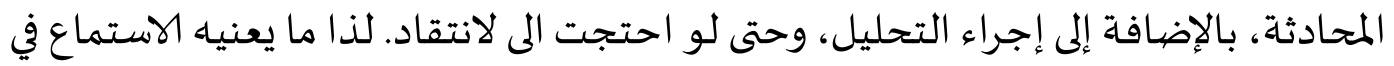

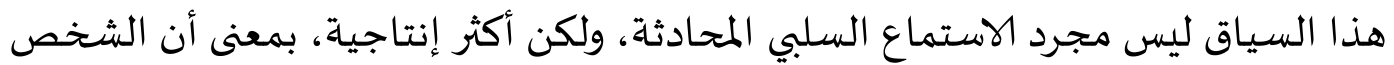

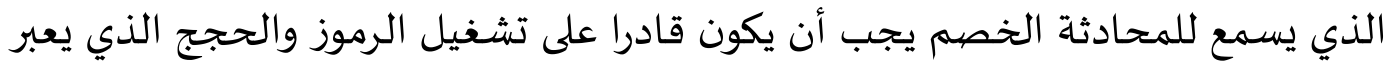
عنها المتكلم، وكذلك تحليل مدى حقيقة صححة وصححة الحجج المطروحة.

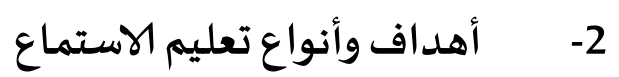
وأما أهداف تعليم الاستماع إلى تحقيق ما يلي : أ- تعويد الأذن على الأصوات الجدات الجديدة. ب- تعويد الدارسين على نطق اللغة الجديدة. ج- استيعاب سؤال للإجابة عليه. د- حل تمرين بتكلم عبارة أو تغيير كلمة أو اضافة أخرى.

5حسن شحائة."تعليم اللغة العربية بين نظرية والتطبيق".( مصدر : دار الدصرية اللبنانية دون سنة).26

${ }^{6}$ Zulhannan," Tekhnik Pembelajaran Bahasa Arab Interaktif",(Jakarta : Pt. Raja Grafindo Persada). hal. 122 


\section{هـ استيعاب نص بتفاصيله للاجابة على أسئيلة.} و- استيعاب الأساسية في نص لتلخيصاه. ز- تتبع العناصر الرئيسية في موضوع لكتابة موضوع على منواله (الإنشاء)

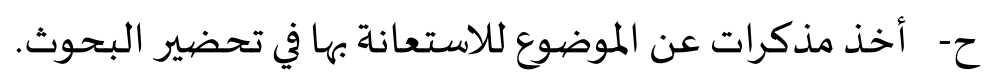

$$
\begin{aligned}
& \text { ط- التمهيد المناقشة موضوع. } \\
& \text { ي- مراجعة مادة سبقت دراستها.7 } \\
& \text { التعليم الاستماع عدة أنواع، وهي : }
\end{aligned}
$$

أ- الاستماع والتركيز، أي الاستماع بإهتمام لما يفعله الشخصيمان ما في حياته في التعليم

$$
\text { والمجتمع، مثل الاستماع إلى الخطب والمواعظ وغيرها. }
$$

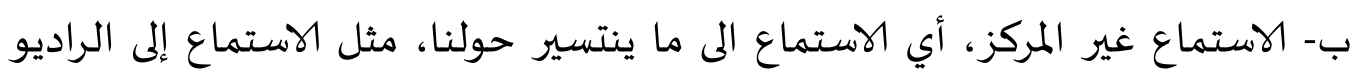

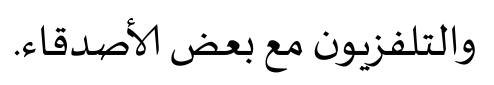

ج- الاستماع بالتناوب، أي مجموعة من الناس الذين يناقشون عنواناً معيناً، وهنا

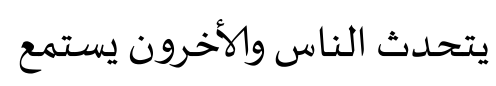

د- الاستماع بالتحليل، وهي تحليل ما سمعه المتحدث. 8

\section{3- مستوى تعليم الاستماع في اللغة العربية}

تعليم اللغة العربية له ثلاثة مستويات منها:

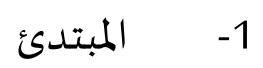

المستوى الأولى في تعليم اللغة العربية، وعادة ما تكون الأنسب لمواد لهذا المستوى هي: يحفظ المفردات، محادثة بسيطة، ويؤدي الاتجاه. وعادة ما يتم استخدامه في المستوى

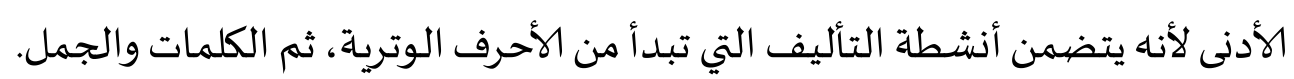

$$
\text { 2 }
$$

في هذا المستوى حصل الطلاب على بعض المواد عن اللغة العربية، ومهمة المعلم في ذلك الوقت هي تعزيز المواد التي حصل عليها الطالب، حتى يتمكن من الكفاءة في المواد.

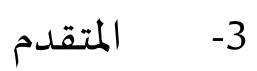

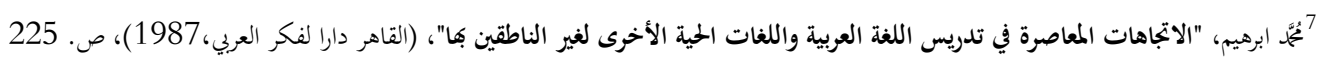

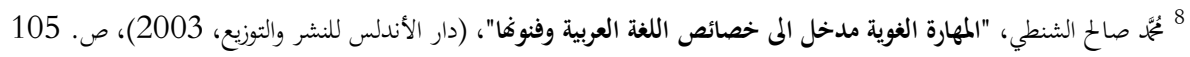


في هذا المستوى بدأ الطلاب يتقنون اللغة العربية والمواد الدراسية المناسبة بأحوال

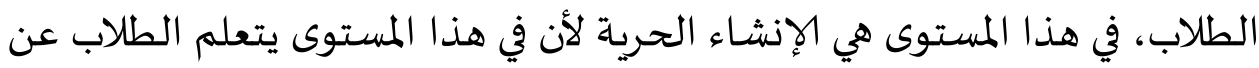

$$
\begin{aligned}
& \text { المهارة والإبداع في الكتابة. } \\
& \text { ب- تقويم تعليم ومباحثها }
\end{aligned}
$$

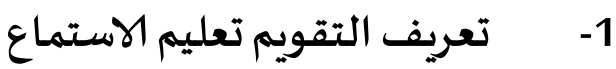

إن مفهوم التقويم يختلف بإختلاف النظرة إلى العملية التربوية. فالنظرة التى تقتصر

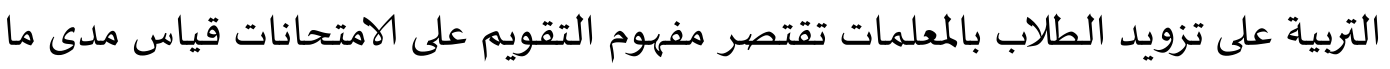
حصله الطلاب من معلومات. والنظرة التي توسع من مفهوم التربية توسع بالتالى من مفهوم التقويم، فيتعدى مجرد الامنحانات إلى قياس مختلف أشكال التغير في سلوك الطلاب معرفيًا ووجدانيًا ومهاريًا (أو نفس حركيًا).

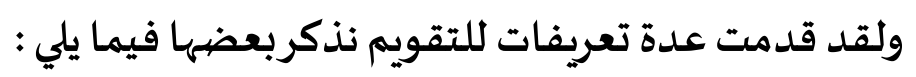

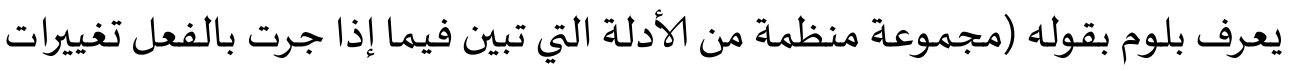

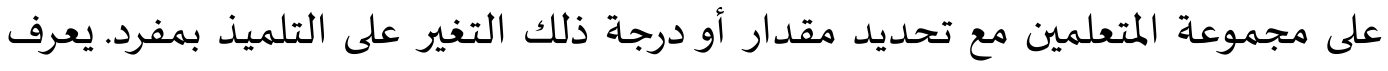

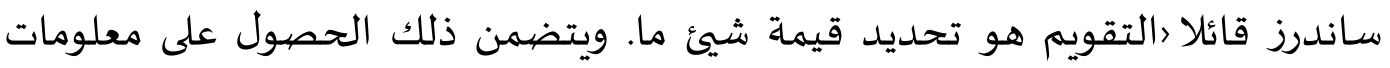

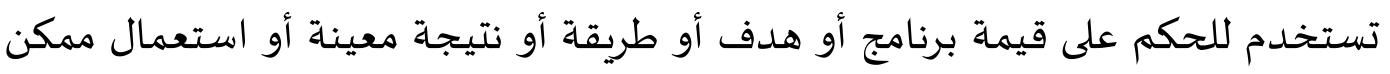

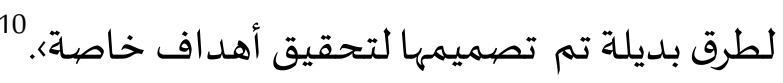

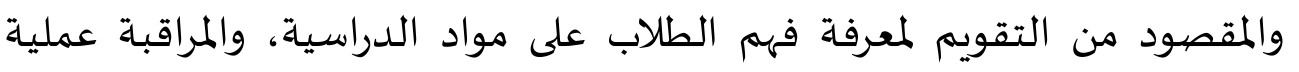
التعليم، ولإعطاء التعليقات كي يكمل تطوير عملية التعليم. يدل التقويم على العملية

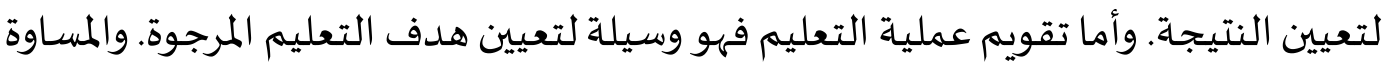

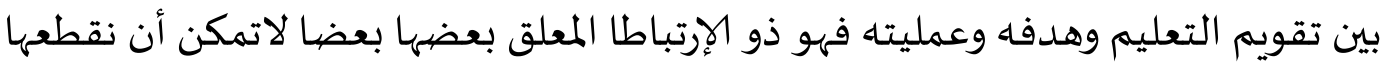
فقط. وهذه هي صورة الإرتباط

\section{2- - المبادئ المهمة لتقويم عملية التعليم منها :}

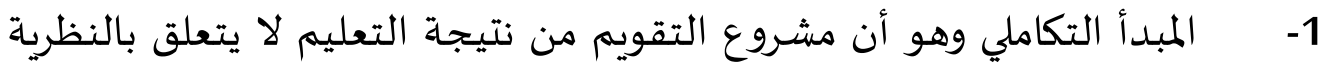

وامعلومات والمهارات فحسب بل يحتوي على نواحي شخصية الطلبة.

${ }^{9}$ M Ainin, “Evaluasi Dalam Pembelajaran Bahasa Arab”, (Malang : Myskat 2006), hal.

$$
\text { "10 رشدى أمد طعيمة. "تعليم العربية والدين بين العلم والفن".(دار الفكر العرى: مدينة نصر القاهر، دون السنة)، ص. } 70
$$


-2 - مبدأ الجماعة وأن المقصود منهاه هو المدرس الذي يرشد الطلبة استمرارا

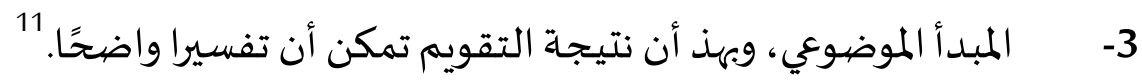

$$
\text { 3- شروط وأهداف التقويم }
$$

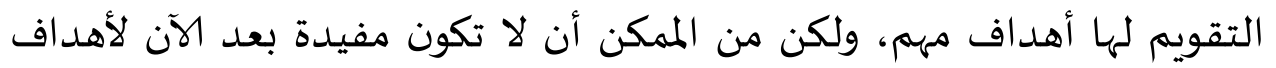

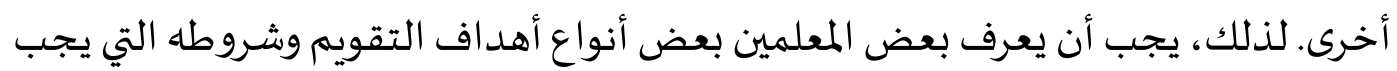
الوفاء بها حتى يتسنى لهم تخطيط وإجراء التقويم بحكمة وبصورة مناسبة.

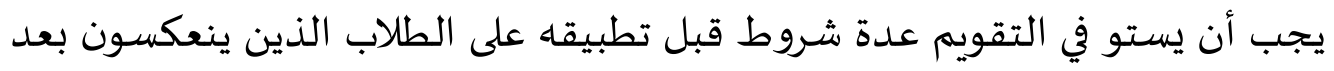

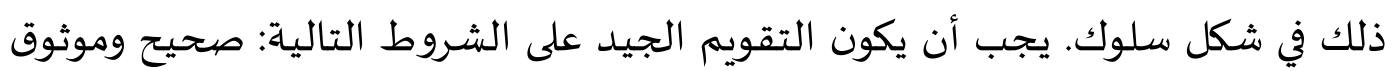

$$
\text { وموضوعي ومتوازن ومتمايز ومعيار وعادل وعملي. }
$$

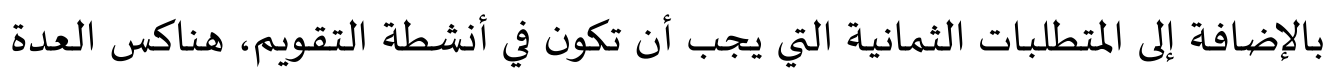

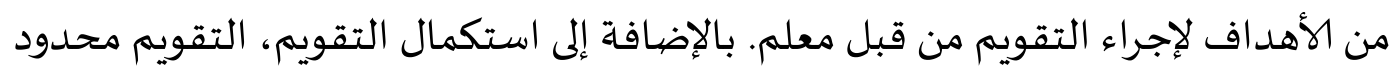

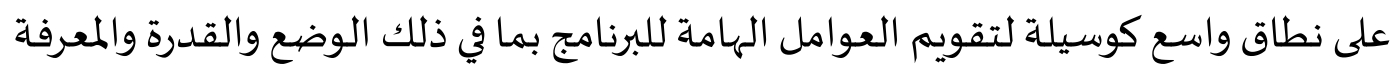

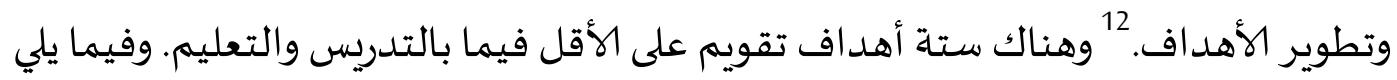

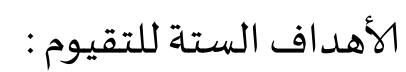
1- تقويم إنجاز (تحقيق) الهدف. هناك صلة بين الهدف من التعليم، وطريقة التقويم، وكيف تتعلم الطلاب، وإلا فإن الهداف من التقويم هو تحديد طريقا هندة التقويم التي

$$
\text { يستخدمها المعلم. }
$$

2- قياس مختلف جوانب التعليم التي تختلف. يتم تصنيف التعليم على أنه معرفي والسلوكى، وسيكوموتور. وتطبق هذه الحدود عموما كمعرفة ومهارات وقيم. يختار

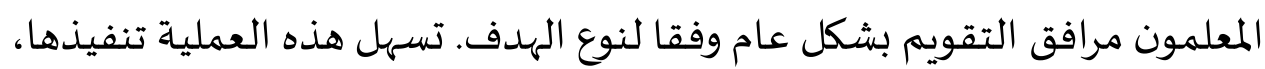

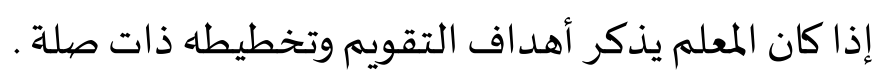

3- كاقتراح (يعني) لمعرفة ما يعرفه الطلاب بعد عملية التعليم. ولطلاب لها إختبار

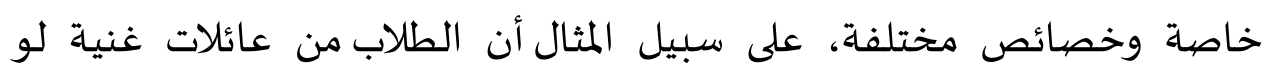

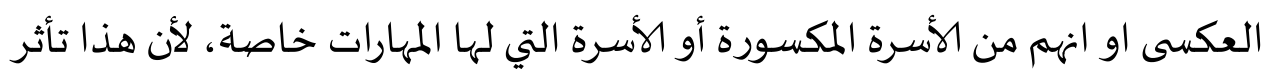

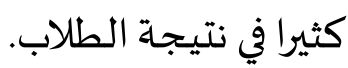

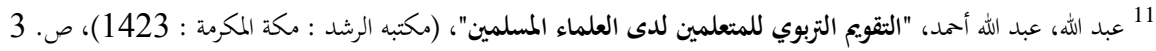

${ }^{12}$ Sukardi, "Evaluasi Pendidikan Prinsip \& Operasional", (Penerbit : Bumi Aksara Jakarta), hal. 8-9 
4- تحفيز تعليم الطلاب. يجب أن يكون التقويم أيضا قادرًا على تحفيز تعليم الطلاب. من البحث المتعددة يظهر أن تقويم تعليم الطلاب تأثرُ لوقت قصير ، ويستفيد قليماً

$$
\text { لوقت طويل في تسجيع الطلاب عند التعليم. }
$$

5- توفير المعلومات لتوجياه والإرشاد. المعلومات معتاجة اليكون التوجيهات فعالة، لاسيما ومعلومات تتعلق بمشاكل شخصية مثل بيانات القدرة، لجودة الشخصيية،و التكيف الاجتماعي، والقدرة على القراءة، ودرجة نتائج التعليم. 6- جعل نتائج التقويم أساساً لتغييرات المناهج الدراسية. العلاقة بين التقويم و التعليم قريب جدا. لأن التقويم جزء من التعليم. 13

$$
\text { 4- مشكلة عملية التقويم }
$$

إن التقويم الجيد هو الذي يلتزم بخطوات الأسلوب العلىى في حل المشكلات.وهو الذي يلتزم المعلم فيه بالأسس العملية سواء عند تحديد أهداف التقويم أو اعداد الأدوات تطبيقها أو جمع البيانات أو تحليلها. 14

\section{ج- تعليم خلال فترة أ- أحوال التعليم خلال فترة الوباء}

الوباء البؤس فيروس كورونا أو المعروف باسم فيروس كورونا أو كوفيد 19 الذي إكتشافه لأول مرة في الصين، وبالتحديد في مدينة ووهان بالصين نهاية عام 2019. وأصبح فيروس فجأة رعبا رهيبا لشعوب العالم، خاصة بعد أن أزهق آلاف الأرواح البشرية في فترة زمنية قصيرة. أقل تقريبًا أكثر من 200 دولة في العالم مصاب بفيروس كورونا تشمل إندونيسيا. ويتخذ العلاج المختلفة لمنع انتشار فيروس كورونا، حتى التباعد الإجتماعي في المدينة و إغلاق. لكسر السلسلة انتشار فيروس كورونا. في لإسلام كان الوباء فيروس كورونا هذا إختبارً لنا لإقترابوا من الله. ويعلم الإسلام إصطلاحا الإعلاق والتباعد الإجتماعي لمنع انتشار المرض، بعض العلماء يسمها با Tho'un وهو الوباء المعدي ويسبب الألم. 15

\footnotetext{
${ }^{13}$ Muhammad Arif Hidayat, "Evaluasi Pembelajaran Panduan Praktis Untuk Memahami Evaluasi”, (Perdana Publishing : 2017), hal. 45 
كان انتشار الوباء كوفيد 19 في جمع أنحاء العالم على الخصوص الإندونسي تأثير كبير على الأنشطة البشرية، وكذلك عملية متعلقة بنشطة التعليمية في المدرسة والتعلمية شخصيًا من مارس 2020 حتى وقت غير محدد. 16 التعليم عبر الإنترنت هو أحد المؤسسات المطبقة في مجال التعليم. في تنفيذ التعليم عبر الإنترنت تواجاه المسكلات، وإحدى منها أن التعليم لا يمكن أن يتم التعليم وجها لوجها في فصول الدراسية. تطلب هذه الحالة من المؤسسات التعليمية الابتكار في عملية التعليم. لذلك، يجب أن يكون ابتكار وإسقاط في المستقبل لمواجهة تحديات التعليم حتى يتمكن من المساهمة في التعليم، منها: أ- القدرة على توفير معلومات التعليم على أساس الشبكة؛؛ ب- تصبح وسيلة في نموذج التعليم على شبكة الإنترنت (على الانترنت) ج- أن تصبح وسيطا في تنفيذ التعليم الإلكتروني؛

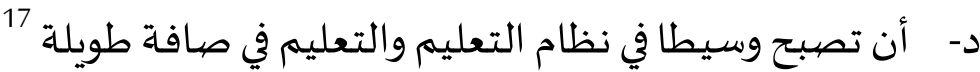

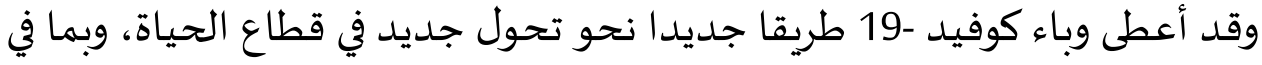

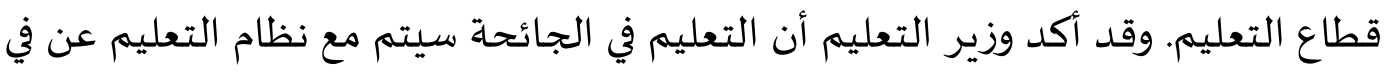

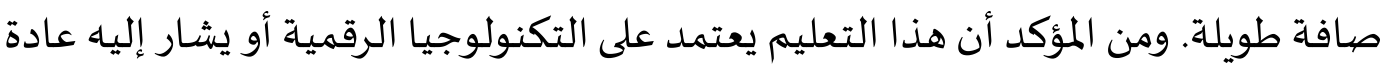

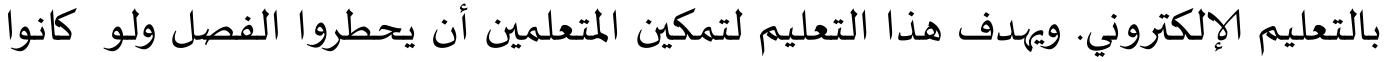

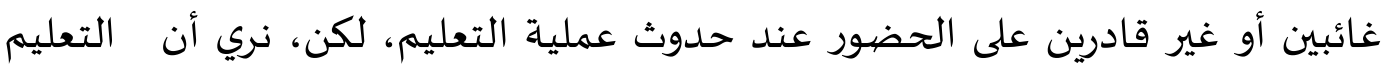
الإلكتروني لا يتم النجاح على الطلاب بسبب عوامل البيئة التعليمية أو خصيائص الطلاب.

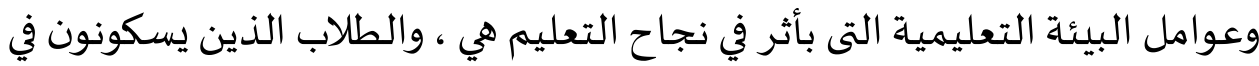

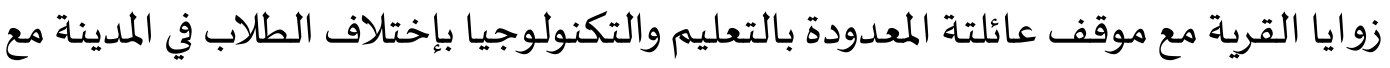
تعليم بأسرة جيدة في الوصول إلى التعليم عبر الإنترنت. 18

$$
\begin{aligned}
& \text { ب- خطوات التقويم خلال فترة الوباء } \\
& \text { حطوات التقويم الرئسية هي : } \\
& \text { 1) وضع المخطط، التي تشمل : ترتيب الشبكة و الاختبار. }
\end{aligned}
$$

\footnotetext{
${ }^{16}$ Yupa.2019." Historical Studies Journal", Diakses Pada Tanggal 15 juli- 2021

${ }^{17}$ Ria Puspita Sari,"Dampak Pembelajaran Darring Bagi Siswa Selama Covid'19”,(Prima Magistra: Jurnal Ilmiah Kependidikan, 2012), hal. 15

${ }^{18}$ Mastura, "Dampak Pandemi Covid-19 Terhadap Proses Pengajaran Bagi Guru dan Siswa”, (Jurnal : Studi Guru Dan Pembelajaran,2020), hal . 289-290
} 
2) تنفيذ التقويم : ترتبط التنفيذ بصورة كبيرة بالجهات المختصة بالتقويم المدرسي

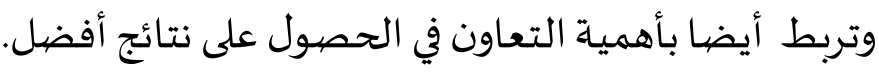
3) معالجة البيانات : مثل معالجة النتائج الإمتحان، و تقويم يومية. 4) تفسير البيانات : هي عملية تستخدم في تحليل و إستخلاص النتائج و تفسيرها.

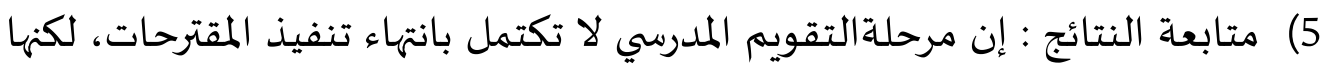

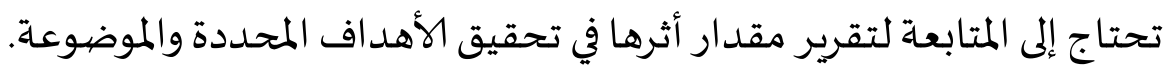
ج- تحليل البيانات ومناقشتها وبعد أن عرض الباحثة البيانات، فأتي بعد تحليلها و تفسيرها، وبإستخدم على البحات البيانات التي قدمها الباحثة في الصفحات السابقة فيحليلها الباحثة أنه بالنظر إلى بيانات تقويم قبل

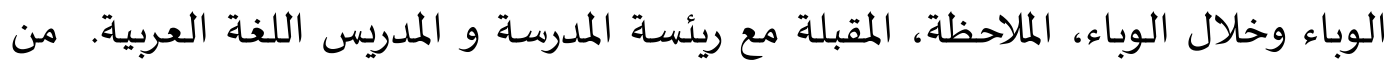
البحث الميداني الذي أجرئته الباحثة المتعلق بتقويم المعلم يعنى : 1- توجد إختلافات في معايير التقويم قبل الوباءو أثناء الوباء

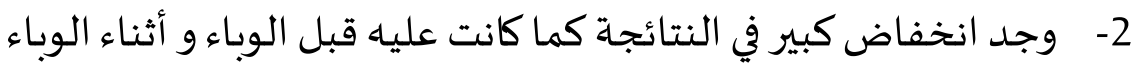
بناء على هذين الأمرين، يقترح الباحثة لإستخدام طريقة التقويم التعليم باستخدام

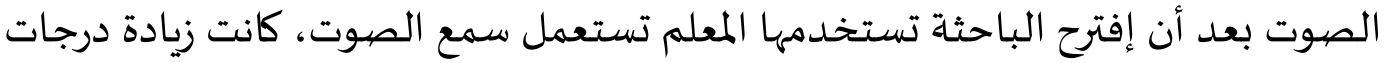

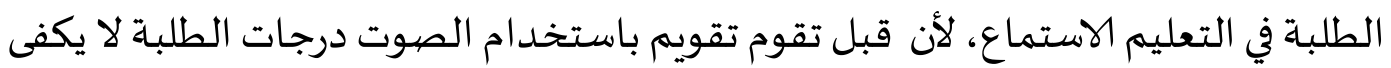

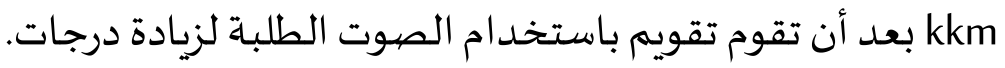

ومن الملاحظة تحصل الباحثة البيانات قبل البدء في التعليم تقرأ الطلبة الدعاء المعلم

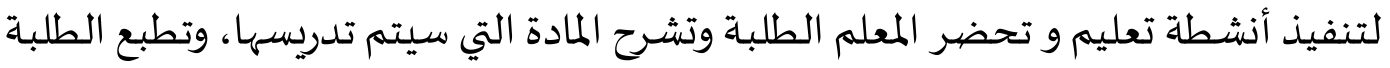
في أنشطة التعليم و التدريس وتفهم المادة التي تدريس المعلم، وتقيم المعلم تقويم.

ومن المقابلة تحصل الباحثة البيانات مشكلات في تعليم اللغة العربية حصوصا الإستماع التي تواجه في تعليم اللغة العربية خلال الوباء عدم وجود تفسير للمادة أثناء عملية التعليم بسب ضيق الوقت الذي يجب على المعلم تفسير شرح المواد. تستخدمها

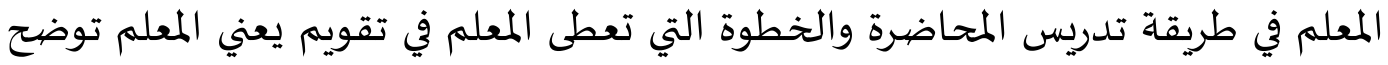
الهداف من التقويم الذي سيتم تنفيذه، وأمر المعلم الطلبة بسامع الإستماع من خلال

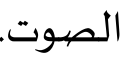


وأما المقبالة مع رئيسة المدرسة خلال الوباء نظام التعليم عبر الانترنت في الوقت التعليم

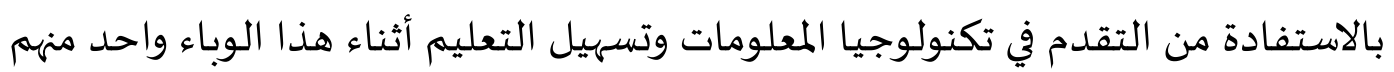
هو zoom، Ghatsapp، و و غيرها. التعليم في خلال الوباء يختلف كثيرا من التعليم الذي

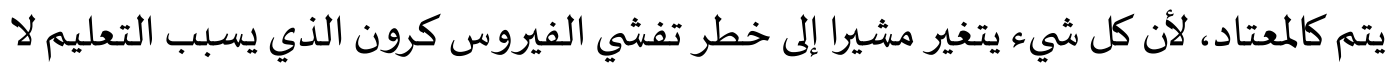

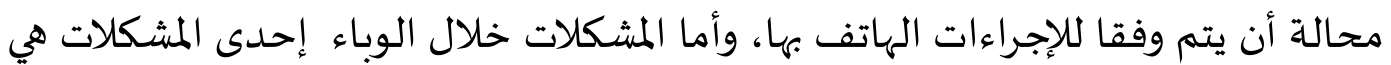
أن تنفيذ التعليم غير فعالية بسبب حدود الوقت.

تحليل الباحثة المتعلقة بيانات المقابلة التي المعلم قد تدرس بشكل جيداديد، والمعلم يعليم

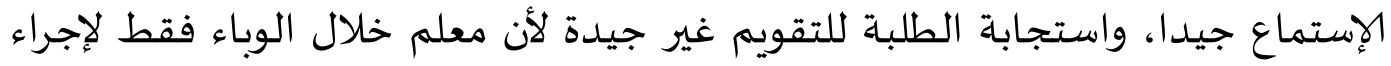
تقويم في امتحانات الفصل الدراسي المتوسطة والغريبة. واستنادا إلى مقابلة تحليل الباحثة مع رئيسة المدرسة، فإن هذه المدرسة جيدة وقد نشأة المأد منذ عام 2011 في فبراير، كما تدعم المدرسة بقوة تعليم اللغة العربية بتوفير البنية التحتية الكافية المتعلقة بتعليم اللغة العربية الإستماع. كما توفر المدرسة مرافق البنية التحتية

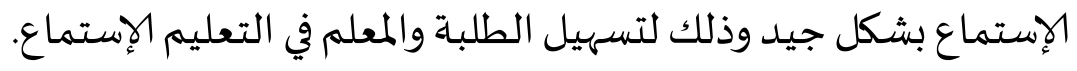

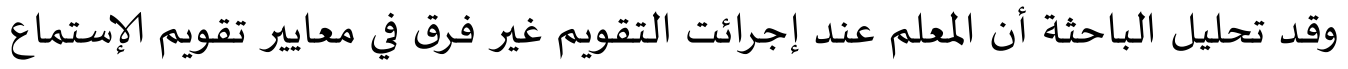
خلال الوباء وقبل الوباء، ومعايير تقويم فيما يلي :

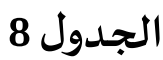

\begin{tabular}{|c|c|c|}
\hline \multicolumn{3}{|c|}{ معييار تقويم } \\
\hline المستوى & مدى الدرجات & \\
\hline & & الرقم \\
\hline ممتاز & $100-85$ & 1 \\
\hline جيد جدا & 84-75 & 2 \\
\hline جيد & $74-65$ & 3 \\
\hline مقبول & $64-55$ & 4 \\
\hline مردود & 5054 & 5 \\
\hline
\end{tabular}


من الجدول أعلاه إلى أنه لا يوجد فرق في معايير التقويم أثناء الوباء وقبله، انها

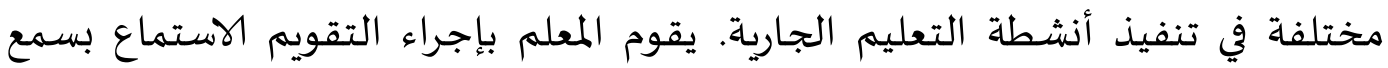
الفيديو وإملاء الفرغ.

لقد بحثت الباحثة في الفصول السابقة فيما يتعلق بموضوع البحث، فتحسن للباحثة أن نعرض نتائج البحث والتوصيات والإفتراحات المتعلقة بهذا البحث وهي فيما يلى: د- نتائج البحث

لقد بحثت الباحثة فب الفصول السابقة بموضوع البحث، فتحسن للباحثة أن نعرض نتائج البحث، وأما نتائج البحث في هذا فئ البحث البحث فيما يلي:

1- إن معايير تقويم تعليم الاستماع خلال الوباء في المعهد الإخوان السلام

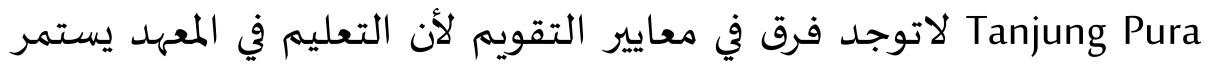
كالعادة تقليل وقت التعليم فقط.

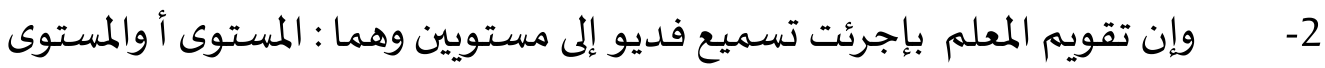

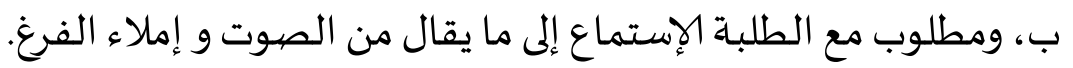

$$
\text { محمد علي الخولى." أساليب تدريس العربية". (بيروت:دار المشرق,2000). }
$$

Suyadi, "strategi pembelajaran pendidikan karakter",(Bandung : PT. Rem ajaRosdakarya, 2013).

Suharsimi Arikunto, "Dasar-Dasar Evaluasi pendidikan", (Jakarta : Bumi Aksara, 2018).

حسن شحائة."تعليم اللغة العربية يين نظرية والتطبيق".( مصدر : دار المصرية

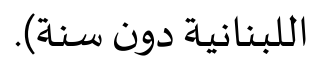

Zulhannan," Tekhnik Pembelajaran Bahasa Arab Interaktif",(Jakarta : Pt. Raja Grafindo Persada).

محمد ابرهيم، "الاتجاهات المعاصرة في تدريس اللغة العربية واللغات الحية الأخرى لغير الناطقين بها"، (القاهر دارا لفكر العربي، 1987). 


$$
\begin{aligned}
& \text { محمد صالح الشنطي، "المهارة الغوية مدخل المى خصيائص اللغة العربية وفنونها"، } \\
& \text { (دار الأندلس للنشر والتوزيع، 2003) } \\
& \text { رشد أحمد طعيمة، محمد السيد مناع. "تعليم العربية والدين بين العلم } \\
& \text { والفن"،ملتمز الطبع والنشر : در الفكر العربي 2001). } \\
& \text { محمد السيد مناع، "تعليم العببية والدين بين العلمر والفن" .(دار الفكر العربي : شارع } \\
& \text { عباس العقاد)مدينة نصر)، }
\end{aligned}
$$

Eman Supriatna.2020. "Jurnal Sosial Dan Budaya Syar'i”, diakses pada tanggal 15 juli 2021

Yupa.2019."Historical Studies Journal”, Diakses Pada Tanggal 15 juli2021

Ria Puspita Sari,"Dampak Pembelajaran Darring Bagi Siswa Selama Covid- '19”,(Prima Magistra: Jurnal Ilmiah Kependidikan, 2012) .

Mastura, "Dampak Pandemi Covid-19 Terhadap Proses Pengajaran Bagi Guru dan Siswa”, (Jurnal : Studi Guru Dan Pembelajaran,2020). 